\title{
From sealing wax to bone wax: predecessors to Horsley's development
}

\author{
Gaurav Gupta, M.D., and Charles J. Prestigiacomo, M.D. \\ Department of Neurological Surgery, New Jersey Medical School, University of Medicine \\ and Dentistry of New Jersey, Newark, New Jersey
}

\begin{abstract}
Object. Writers of neurosurgical history have traditionally maintained that the initial use of cranial bone wax for hemostasis in humans was developed and promoted by Sir Victor Horsley, the father of British neurosurgery. A thorough literature review, however, suggests that the use of bone wax for cranial bone hemostasis had its roots more than 50 years before Dr. Horsley's description in 1892. In this study the authors review the sources addressing this issue and establish due credit to the surgeons using bone wax for cranial bone hemostasis before Horsley.

Methods. Primary and secondary general surgery and neurosurgery literature from 1850 to the present was comprehensively reviewed. The key words used in the literature searchers were "bone wax," "sealing wax," "cranial surgery," "Victor Horsley," "hemostasis," and "bone hemostasis."

Results. Although Dr. Horsley's description in 1892 clearly delineates the necessary formula for creating a soft, malleable, nonbrittle wax that would easily promote hemostasis, the literature suggests that sealing wax was commonly used as early as 1850 for hemostasis in cranial bones. Even though there is documentation that Magendie (1783-1855) used wax to occlude venous sinuses in animals, detailed documentation of the constituents are not available. Evidence reveals that surgeons like Henri Ferdinand Dolbeau (1840-1877), professor of external pathology and the surgical clinic (1868-1872) at the Paris hospitals, used bone wax in 1864 for the extirpation of a frontal osteoma/exostoses of the frontal sinus.

Conclusions. The use of bone wax in cranial surgery was described by Henri Ferdinand Dolbeau, 50 years prior to Sir Victor Horsley's report in 1892. Nonetheless, it was Horsley who advocated and popularized its use in neurological surgery as an additional tool in the hemostatic and surgical armamentarium. (DOI: $10.3171 / \mathrm{FOC}-07 / 07 / \mathrm{E} 16)$
\end{abstract}

KEY WORDS • bone wax • cranial surgery • hemostasis • Victor Horsley

A CHIEVING proper hemostasis is an essential principle of surgery. Neurosurgeons, in particular, face a more difficult challenge in that hemostasis must be achieved across many tissue types with unique physical and biological properties. Tissues of the scalp, bone, and brain require specific techniques to achieve the proper result without extensive tissue damage.

Achieving adequate hemostasis in bone was particularly important in neurosurgery because of the tremendous vascularity of the diploë. Sir Victor Horsley (1857-1916) has been credited with introducing the use of bone wax into neurosurgery in $1892 .{ }^{8}$ However, there is evidence to suggest that this technique was in use almost 50 years prior to Horsley's application. In this review we present evidence from the scientific literature revealing the use of wax before Horsley's well-known published communication, and we describe the reasons that Horsley is ultimately given credit for this contribution to the then fledgling field of neurosurgery.

\section{The Early Years}

The techniques for achieving hemostasis in bone varied according to the anatomical location. Thus, the methods applied to the extremities, such as cautery, were not as suitable to regions such as the cranial vault, in part because of the vascularity of the diploë and also because of cosmesis. Surgery on the scalp and face had advanced little since the work of Ambrose Paré in the mid-16th century. The only cranial operation regularly performed at that time was trephining, which had been used since prehistoric times. Evidence suggests that hemostasis following cranial trephination was traditionally achieved by local pressure with various admixtures of herbal ingredients. In the 18th century, modeling or candle wax became fashionable for surgeons to use in controlling bleeding from cranial bones. For example, in 1757, Belloq reported several methods of stopping certain hemorrhages in the head. ${ }^{6,14} \mathrm{He}$ applied candle wax to stop severe hemorrhage after tooth fracture or tooth extraction; his description may represent one of the earliest references to the use of wax in the craniofacial bones.

\section{The 19th Century}

Almost a century later, Professor Khristian Khristianovich Salomon (1796-1851), head of the Academy Surgical Clinic in Russia in 1840, proposed the use of wax to arrest bleeding from cranial bones. ${ }^{12}$ In his text A Manual on Operative Surgery ${ }^{11,21}$ (written in Russian in 1840), he 


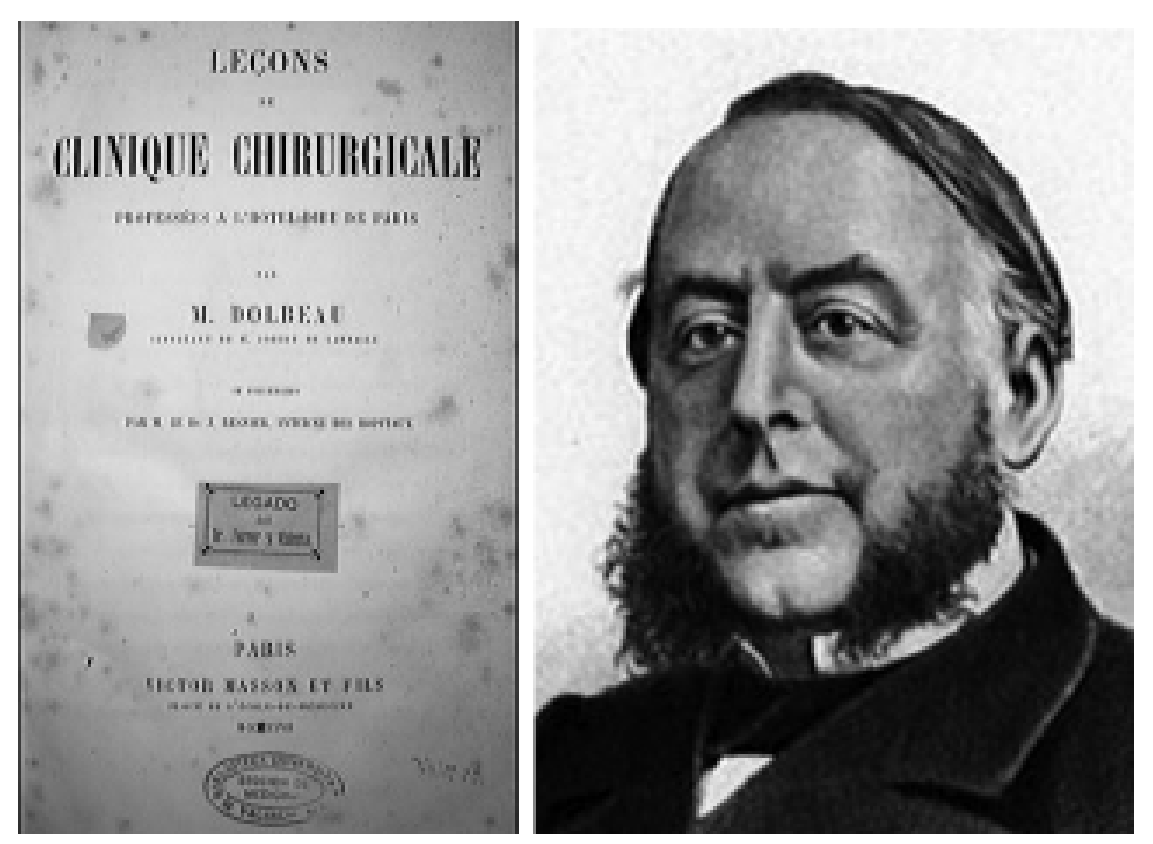

FIG. 1. Left: Image showing the front of Dolbeau's Leçons de clinique chirurgicale professees a l'Hotel-Dieu de Paris, which dates back to a time when Victor Horsley, who was born in 1857, was only 7 years old. Right: Image depicting Henri Ferdinand Dolbeau (1840-1877), professor of external pathology and the surgical clinic (1868-1872) at the Paris hospitals.

summarized the progressive research experience of that time, testifying to the high level of Russian surgery in the 19th century. The results of using ordinary modeling/candle wax were not optimal, however, given the lack of sterility and malleability of the wax. It is quite interesting to note that this technique was described a full 50 years before Horsley's description in the the British Medical Journal.

In addition to Russia's contribution to the use of wax to control hemostasis after cranial surgery, anatomists and clinicians in France had applied the use of wax for hemostasis in the mid-19th century. First, François Magendie (1783-1855) used wax to close venous sinuses ${ }^{9,25}$ in his experimental animal models, and his method subsequently passed into the operative suite. Horsley specifically mentions this event as a primary influence in his introduction of bone wax into the nascent field of neurosurgery.

Interestingly, Henri Ferdinand Dolbeau (1840-1877), a distinguished French surgeon, in 1864 was one of the first physicians to operate successfully on an osteoma of the frontal sinus. In a report delivered by Richet ${ }^{5,19,25}$ in 1871 at the meeting of the Paris Academy of Medicine on "Dolbeau's lecture on the exostoses of the frontal sinus," which had been read at the Academy of Medicine in September 1866, it was stated: "we were obliged to play with a ball of wax in the orifice of a major artery lying on the surface where the tumor was implanted which gushed blood." Dolbeau's operation in 1864 dates back to a time when Victor Horsley, who was born in 1857, was only 7 years old, ${ }^{16,25,26}$ and in his publication Dolbeau describes having used wax for hemostasis during extirpation of this lesion with good results (Fig. 1). Consequently, it has been noted that Dolbeau preceded Horsley in the use of bone wax by several years, ${ }^{24,25} \mathrm{a}$ fact that is recognized by Bucy ${ }^{3}$ in an editorial note.

In his 1896 book A Treatise on Surgery, Roswell Park writes, "a number of years ago, Gunn suggested the use of wax for this (stopping bleeding from bone) purpose,... being plastic and incapable of absorption. A piece of white wax was heated in hot water, molded with the fingers to fit the cavity, where it served the purpose of a packing." ${ }^{17}$ This description also suggests that the use of wax for hemostasis occurred several years prior to Horsley's description.

\section{Horsley's Contribution}

Sir Victor Alexander Haden Horsley, regarded by many as one of the founders of British neurosurgery, was appointed to the Brown Institution of the University of London in 1884, where he performed extensive experiments on the localization of brain function. Horsley conducted his own experiments on the cranial bones of dogs but was dissatisfied with the results, and thus he asked P. W. Squire to assist him. It was Squire who came up with the formula of using beeswax instead of ordinary modeling wax in a preparation that later came to be called "bone wax." The material was kept in stoppered bottles and was sterilized by boiling. ${ }^{7}$ The first documented evidence of the successful use of bone wax in clinical surgery appeared in the May 21, 1892, edition of the British Medical Journal; Rushton Parker used it to stop bleeding from the lateral sinus. ${ }^{18}$ In his paper, he gives thorough credit to Victor Horsley for providing the wax (Fig. 2): "The lateral sinus was scraped, and sublimate solution syringed freely through the sinus, and the stump of the jugular vein and other exposed parts. On probing the sinus upwards, 
LIVRRPOOL ROYAL INFIRMATY.

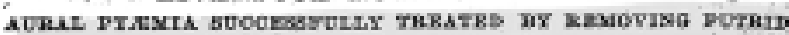

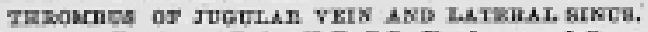
(By Rukrxow PAnkre, B.8. F.R.C.S. Professor of Surgery in University (College, Liverpool.)

A survin, who had been kicked is the left ear at 'the age of 14 , and had cccasional aubeeguent discharge of otvinglve matter, was admitted into bospital ander the care of $\mathrm{Dr}$. Catob, aboat August 18th, 180t, having suffered pain in the affected ear for a week previonsly, and for three days rigors, vomiting, The evenisg of admisason, falling to $10^{\circ}$ next morning. He felt gidey whes sttempting to wall, but in bed, where be was kept, he was Arowky nast of the time, with oocasional defiring. The left ear was slmost entirely deaf, discharging fortid pus. Thers was smelting and tenderness of the reok over the upper part of the jagalar vein, but none of the mastotd region. Bvergthing gurgpsted that plugging of the totd regton. Bverything suxgpsted that plugging of the state of the laternl sinus, and that, in fact, phlebitis pyrmia existed. Double optis neuritis was found, more on the right then lert, and it was agreed on censultalion that the man"s only prospect of escape lay through the radical operation practiapd by Mr. Arbuthot Lave in 1898 sad 1899, snd by Fractiard by Mir. Ar

Mr. Parker feela findebtod to Mr. A. Macleod Foss for having drawn bia attention to the reports-overlooked at the time of publication-of this most important operation, in time for the first opportasity he has had of putting it into practioe.

A teagt four rigors cocurred daring turo dnys in hospital nad anotber of severe kind, with chattiring of the teeth, came on while the patiens wab beine conveypd to the operating thentre.

Under chloroform on Auguat 218t, 1891, an incision 7 or 8 inches long was made down to the lefi jugalar vein sad mas. toid process. The vein was found firmly plugeed from the hase of the ekull to below the junction with the facisil trask, alko plagesed for $\mathrm{en}$ inch or so. Both veins were cat beturees two ligatares in their healthy parts, and their plagied portion raiaed alobg with a erop of awollen lymph glanda that, no doubt, socounted for the swelling of the neok. The mastoid rezion was opened with gouge nad mallet, and emitted a verg foul odogr from the lateral ainus thus exposed, and now found dieorganised and oceapied by growen porulent lymph, with tho tnil end of a purple bleod clot that tiaickusul form. wards. The detached firmly distended jugular was opened, being lined with adherent grey membranoua lymph aarioasd. ing a solid plug at purple blood elob, partly bottened and puriform within. The thrombosed vein was cut away, excent slout an inch sttached to the base of the akull, of which remaining portion the lymplyy lining mas ecraped off. The lateral ginus was sciraped, and aublimate solution syringed. freely through the ginus, and the stamp of the jugular vein and other exposed varts. On brobing the fings gpwands bloed foust freely, bet antiseptic max (of cocnookition unknown to me; bat kindly provided by Mr. Viotor Hersley and Mears. Bqaire). The lower balf of the wound was atitched, and healed at once by first intention; the upper half, and the parts about the ear, were loept opea and dressed with eranire muse

FIG. 2. Image of the original article written by Rushton Parker in which he describes the use of bone wax that was "kindly provided by Mr. Victor Horsley and Messrs. Squire" and which was published in the British Medical Journal in the May 21, 1892, edition. (Image courtesy of the British Medical Journal.).

blood flowed freely, but was easily stopped with a plug of antiseptic wax (of composition unknown to me, but kindly provided by Mr. Victor Horsley and Messrs. Squire)."

When asked to comment, Horsley ${ }^{9}$ wrote in his correspondence, which was published in the May 28, 1892, volume:

\section{Sir,}

The antiseptic wax which Mr. Rushton Parker refers to on page 1076 of the British Medical Journal of May 21st has the following composition: beeswax, 7 parts; almond oil, 1 part; salicylic acid, 1 per cent. It is the outcome of experiments made in 1885, when, remembering the practice of Magendie and others at the commencement of the century in stopping the sinuses with wax, I tried the effect of "smudging" modelling wax worked soft in the fingers on the free bleeding cut surface of the cranial bones in dogs. As such a process instantly arrested the bleeding, I tried to make an antiseptic compound for operations on man, and the formula was published. It was not, however, satisfactory in my opinion, and I asked Mr. P. W. Squire kindly to make experiments so as to arrive nearly at the tenacity of modelling wax. This, I think, he has perfectly succeeded in with the above formula. I have very often used it, and without the least inconvenience. I need hardly say that it is always sterilised by boiling before use, and kept in covered stoppered bottles.-I am, etc.

This brief communication by Horsley became the source for his subsequent credit for the invention of bone wax. Indeed, M. Allen Starr's ${ }^{23}$ textbook on brain surgery, published 1 year after Horsley's description, specifically refers to "Horsley's wax" as the material to use in situations of diploic bleeding refractory to gentle pressure. Interestingly, he also lists alternative means to hemostasis in this description, including local pressure with a sponge, a plug of decalcified bone, a plug made from an aseptic sponge, or direct crushing of the inner and outer tables directly on the diploic vein.

Despite its popularity, Horsley's bone wax was not free from complications. Bone wax was noted to potentially cause chronic inflammation, $2,7,10$ act as a mechanical barrier to bone regeneration,,$^{1,20,22}$ lower the bacterial clearance in cancellous bone, precipitate the formation of a foreign body granuloma, ${ }^{13}$ and migrate into the sigmoid sinus. ${ }^{8}$ Concerns over these undesirable properties prompted research into the development of alternative hemostatics. ${ }^{15}$ In $1900 \mathrm{Crile}^{4}$ proposed a modification to Horsley's formula. Fifty years later, Geary and Frantz ${ }^{7}$ described a resorbable polyethylene glycol composite as a vehicle to deliver a hemostatic agent - oxidized cellulose. Instead of beeswax, they used carbowax. They compared their material to original bone wax in a rib fracture model. Polyethylene glycol-tamponaded bleeding bone was resorbed and caused only a minor inflammatory reaction. Of historical importance is the fact that today's bone wax, which is made of $88 \%$ refined beeswax and $12 \%$ isopropyl palmitate, is remarkably similar to that developed by Squire and Horsley.

\section{Conclusions}

Technology and innovation builds on the successes and failures of the past. The use of bone wax in neurosurgery was certainly popularized by Horsley's timely contribution to the literature. The debates regarding the first use of bone wax in neurosurgery may continue, as they do in trying to determine whether Horsley or Cushing was the first to use muscle as a hemostatic agent. However, there is pervasive evidence that the use of bone wax to achieve hemostasis in bone was not conceived by Horsley, who himself points to earlier pioneers such as Magendie and Gunn as specific influences for this idea. Mitigating circumstances such as the presentation of this concept in the English literature for the first time, the inherent difficulties in keeping up with the world literature at that time, and the obvious endorsements from emerging experts like Starr and Cushing in what was a new field likely resulted in Horsley's name being nearly synonymous with bone wax. 


\section{References}

1. Aurelio J, Chenail B, Gerstein H: Foreign-body reaction to bone wax. Report of a case. Oral Surg Oral Med Oral Pathol 58: 98-100, 1984

2. Brightmore TG, Hayes P, Humble J, Morgan AD: Haemostasis and healing following median sternotomy. Langenbecks Arch Chir Suppl:39-41, 1975

3. Bucy P: Editorial Note: Henri-Ferdinand Dolbeau-1840-1877. Surg Neurol 18:215, 1982

4. Crile GW: Observation on the surgery of the brain based on clinical and experimental evidence. M Rec 57:270-273, 1900

5. Dolbeau $\mathrm{H}$ : Leçons de clinique chirurgicale professées à l'Hôtel-Dieu de Paris, recueillies par J. Besnier. Paris: G. Masson et fils, 1867, Vol 1, p 438

6. Feldmann H: [Nosebleed in the history of rhinology. Images of the history of otorhinolaryngology presented by instruments from the collection of the Ingolstadt Medical History Museum.] Laryngorhinootologie 75:111-120, 1996

7. Geary JR, Frantz VK: A new absorbable hemostatic bone wax; preliminary report. J Neurosurg 7:383-384, 1950

8. Hadeishi H, Yasui N, Suzuki A: Mastoid canal and migrated bone wax in the sigmoid sinus: technical report. Neurosurgery 36:1220-1224, 1995

9. Horsley V: Antiseptic wax. Br Med J:1165, 1892

10. Howard TC, Kelley RR: The effect of bone wax on the healing of experimental rat tibial lesions. Clin Orthop Relat Res 63: 226-232, 1969

11. Karavayeva A: Operative Manual of Surgery. Kiev, 1886, p 211 (Reference provided by E. N. Konadakov)

12. Kondakov EN: History of Home Neurosurgery: Some Pages Part II, in Kondakov EN (ed): Saint Petersburg, Russia: Polenov Research Neurosurgical Institute. Saint Petersburg, Russia, Vol 2005

13. Low WK, Sim CS: Bone wax foreign body granuloma in the mastoid. ORL J Otorhinolaryngol Relat Spec 64:38-40, 2002

14. Malgaigne J: Operations on the teeth, in Operative Surgery. Philadelphia: Blanchard and Lea, 1851, p 96

15. Orgill DP, Ehret FW, Regan JF, Glowacki J, Mulliken JB: Poly- ethylene glycol/microfibrillar collagen composite as a new resorbable hemostatic bone wax. J Biomed Mater Res 39: 358-363, 1998

16. Paget S: Sir Victor Horsley_A Study on His Life and Work. London: Constable and Co. Ltd, 1919, Vol. 1, p 358

17. Park R: Surgical diseases of the Osseous system, in Park R (ed): Treatise on Surgery. Philadelphia: Lea Brothers and Co., 1896, p 671

18. Parker R: Aural pyaemia successfully treated by removing putrid thrombus of jugular vein and lateral sinus. Br Med J. May 21, 1892

19. Richet C: Rapport sur un travail de M. Dolbeau intitule: Memoire sur les exostoses du sinus frontal. Bull de l'Acad Med 36:564-599, 1871

20. Rockwood C, Perkins JC, Roberts L, Dixon D: Reaction of bone wax on bone and muscle. J Bone Joint Surg 50:837-838, 1968

21. Rukovodstvo SL: A Manual of Operative Surgery, ed X.X. St. Petersburg, 1840, Vol II (Rus) (Reference by E. N. Kondakov)

22. Sorrenti SJ, Cumming WJ, Miller D: Reaction of the human tibia to bone wax. Clin Orthop Relat Res:293-296, 1984

23. Starr MA: Brain Surgery. New York, NY: Wood, 1893

24. Steimle R: L'emploi de la cire pour l'hemostasis osseuse en neurochirurgia. Hist Sci Med 15:39-43, 1981

25. Steimle R: A note on the use of wax for bone hemostasis. HenriFerdinand Dolbeau (1840-1877). J Hist Neurosci:243-244, 1993

26. Walker A: A History of Neurological Surgery, Vol 1. Baltimore: Williams and Wilkins, 1951, p 583

Manuscript submitted May 15, 2007.

Accepted May 22, 2007.

Address reprint requests to: Charles J. Prestigiacomo, M.D., Departments of Neurological Surgery and Radiology, Neurological Institute of New Jersey, New Jersey Medical School, University of Medicine and Dentistry of New Jersey, 90 Bergen Street, Suite 8100, Newark, New Jersey 07101-1709. email: presticj@umdnj.edu. 